\title{
Do mito malthusiano ao das relações recíprocas - a constituição interdisciplinar do campo de População e Ambiente
}

\author{
Álvaro de Oliveira D’Antona*
}

O artigo faz uma revisão sobre a constituição do campo de População e Ambiente (P-A), sobretudo nos anos 1990, por meio da prospecção de artigos em bases internacionais indexadas, da identificação das instâncias estruturantes do campo, essenciais para a sua identidade e validação do conhecimento produzido, e do apontamento da relação do campo com as temáticas de população, desenvolvimento e ambiente presentes nas conferências da ONU. Como resultado, observa-se que a produção científica publicada nas principais revistas e eventos de estudos de população progressivamente se afastou do mito malthusiano, voltando para a busca das relações recíprocas entre população e ambiente, um segundo mito. Constata-se ainda a existência de questões e eixos característicos, identitários, tratados por um conjunto bem definido de cientistas. Entre os dois mitos essenciais, P-A expandiu-se como um campo interdisciplinar sob efeitos dos diálogos com as ciências sociais e as ambientais. Insubordinado a limites disciplinares, enfrenta as dificuldades teórico-epistemológicas e empíricas de um campo ainda em formação, enquanto experimenta as tensões com a demografia, disciplina importante da sua matriz programática.

Palavras-chave: População e ambiente. Demografia. Pesquisa. Pesquisadores. Campo.

\footnotetext{
*Universidade Estadual de Campinas (Unicamp), Faculdade de Ciências Aplicadas (FCA), Limeira-SP, Brasil (alvaro.dantona@ fca.unicamp.br).
} 


\section{Introdução}

A especificidade do campo de População e Ambiente (P-A) reside na busca do entendimento de relações, ou efeitos recíprocos, entre as variáveis de população $(P)$ e as de ambiente (A). De forma emblemática: $P\langle->A$. 0 desafio que reside nas setas - encontrar e expressar os nexos entre os dois termos - torna o campo essencialmente interdisciplinar, ainda que tenha se constituído a partir de referências das ciências sociais, particularmente da demografia. ${ }^{1}$

Em reação à perspectiva neomalthusiana, o desenvolvimento do campo deu grande impulso, nos anos 1990, a uma agenda de pesquisa que estimulava incorporar às análises outros componentes da dinâmica demográfica (principalmente a mobilidade) e a distribuição espacial da população. Tal agenda confrontou o monocórdico discurso (quase-mantra) da "bomba demográfica", colocando o foco nas relações recíprocas, o que demandou visões mais integradas das dimensões sociais dos problemas ambientais.

Essa construção, de certa forma, foi uma reação ao modo como a demografia vinha tratando as questões ambientais, como se pode observar na crítica de Hogan (1991, p. 61):

Mas de que maneira a demografia tem abordado esta relação? E como os esforços de pesquisa podem ser dirigidos para otimizar a contribuição da disciplina ao desafio ambiental? Antes de avançar muito na resposta a esta pergunta, é preciso examinar com cuidado como a relação tem sido apresentada. É minha tese que não temos muitos resultados para dois séculos de trabalho.

No presente artigo, propõe-se uma revisão da constituição desse campo, sendo o termo “campo" tomado de Bourdieu (1976, 2004) em referência a um conjunto de forças e de disputas constituído por pessoas, instituições e mecanismos de validação do conhecimento produzido. A caracterização de P-A é aqui desenvolvida por meio da prospecção de artigos em bases internacionais indexadas, da identificação das instâncias estruturantes do campo e do apontamento da relação do campo com discussões mais gerais em torno das temáticas de população, desenvolvimento e ambiente abordadas nas conferências da ONU.

A tensão entre o campo interdisciplinar e a sua principal referência, a demografia, está latente em todo o texto e conduz à provocação final sobre a insubordinação de P-A. Em seu cerne está o trânsito entre dois mitos essenciais para o arcabouço do campo: o malthusiano e o das relações recíprocas. ${ }^{2}$

\footnotetext{
${ }^{1} \mathrm{~A}$ inter-relação dos termos e a interdisciplinaridade aqui advogada se condicionam às escalas de análise, sobretudo nas abordagens multiescalares - a respeito, ver reflexões em Walsh (1999), Bremmener e Bilsborrow (2005) e Barbieri (2007), dentre outros.

20 mito como um fragmento de uma narrativa maior é aqui evocado mais livremente a partir do referencial do antropólogo Claude Lévi-Strauss (1963,1975). Almeida (1999), ao analisar a obra de Levi-Strauss, acrescenta: “Também os mitos morrem. Um mito que se transforma em outros respeita os invariantes do grupo de transformações a que pertence até que se cansa. Como ondas que a pedra criou no lago: a forma circular se amortece com a distância e com o tempo, até deixar de ser distinguível no movimento da água sob a brisa da manhã”.
} 


\section{Um campo em expansão}

Tendo como termo de consulta "população e ambiente" OR “population and environment", uma análise exploratória da produção científica entre 1996 e 2015 registrada na base de dados Scopus retornou 5.374 artigos científicos. ${ }^{3}$ Dentre eles, predominam os classificados na área (subject area) de ciências sociais (social sciences) e/ou na de ciências ambientais (environmental science), com 4.020 artigos. Um elenco diverso de áreas completa a lista, sendo as principais delas, em ordem decrescente de ocorrências: agricultural and biological sciences; earth and planetary sciences; medicine; economics, econometrics and finance; business, management and accounting; psychology; engineering, arts and humanities; energy; biochemistry, genetics and molecular biology; computer science; mathematics $e$ multidisciplinary.

Considerando apenas os artigos classificados em pelo menos uma das duas áreas principais, o levantamento revela o crescente uso do termo "população e ambiente" nos anos 2000. 0 número de artigos subiu de pouco mais de 100 por ano, em 1996, para mais de 600 ao ano no final do período considerado. Passando para os 2.788 artigos da vertente das social sciences filtrados do subconjunto anterior, verifica-se similar crescimento no número de publicações ao longo do tempo (Gráfico1A). Como um mesmo artigo pode estar vinculado a mais de uma área, vê-se a articulação das ciências sociais com outras subject areas, principalmente com environmental science e com as áreas de saúde, tecnológicas e economia (Gráfico 1B).

Com 390 artigos científicos listados no período analisado, a principal revista é a Population and Environment (Poen), ISSN 0199-0039, editada pela Springer. Com 18 artigos, a Revista Brasileira de Estudos de População (Rebep), ISSN 0102-3098, é o periódico brasileiro com maior número de artigos. Quando se desconsidera a revista Population and Environment, o crescimento anual de artigos se mantém (a participação dos textos da revista é pequena em relação ao total), significando que o aumento no uso do termo não se deve apenas a tal revista.

Entre as 25 principais revistas em números de artigos publicados (1.253), predominam as de demografia/estudos de população, geografia, economia/administração, além daquelas que podem ser classificadas como das ciências ambientais (Tabela 1). Uma parte das revistas se apresenta como multi ou interdisciplinar, enquanto outras se classificam como disciplinar - ainda que todas, em variados graus, publiquem artigos com questões interdisciplinares.

\footnotetext{
${ }^{3}$ Disponivel em:/http://www.scopus.com/>. Acesso em: 5 ago. 2015. A base Scopus foi escolhida por incluir mais periódicos brasileiros relevantes ao estudo do que a WebofScience.
} 


\section{GRÁFICO 1 \\ Artigos da área de Ciências Sociais com o termo "População e Ambiente” 1996-2015}

\section{A. Número de artigos por ano}

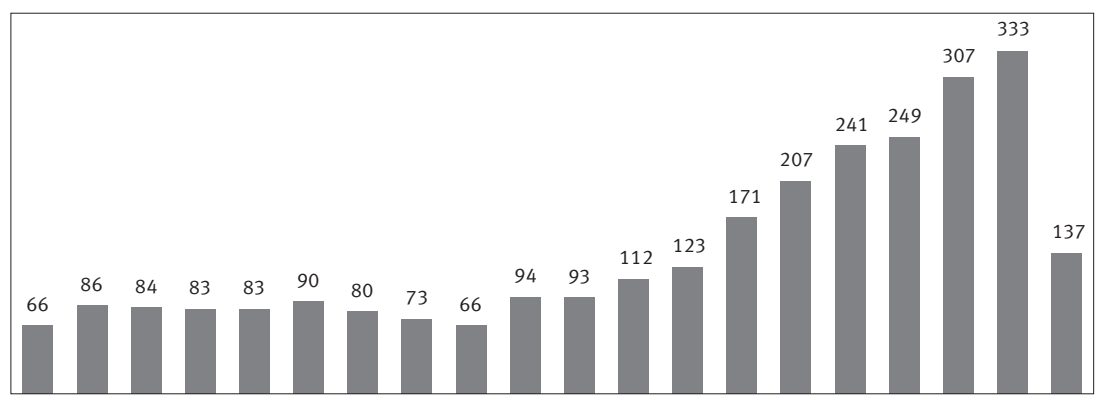

19961997199819992000200120022003200420052006200720082009201020112012201320142015

Artigos por ano

\section{B. Áreas (subject areas) dos artigos}

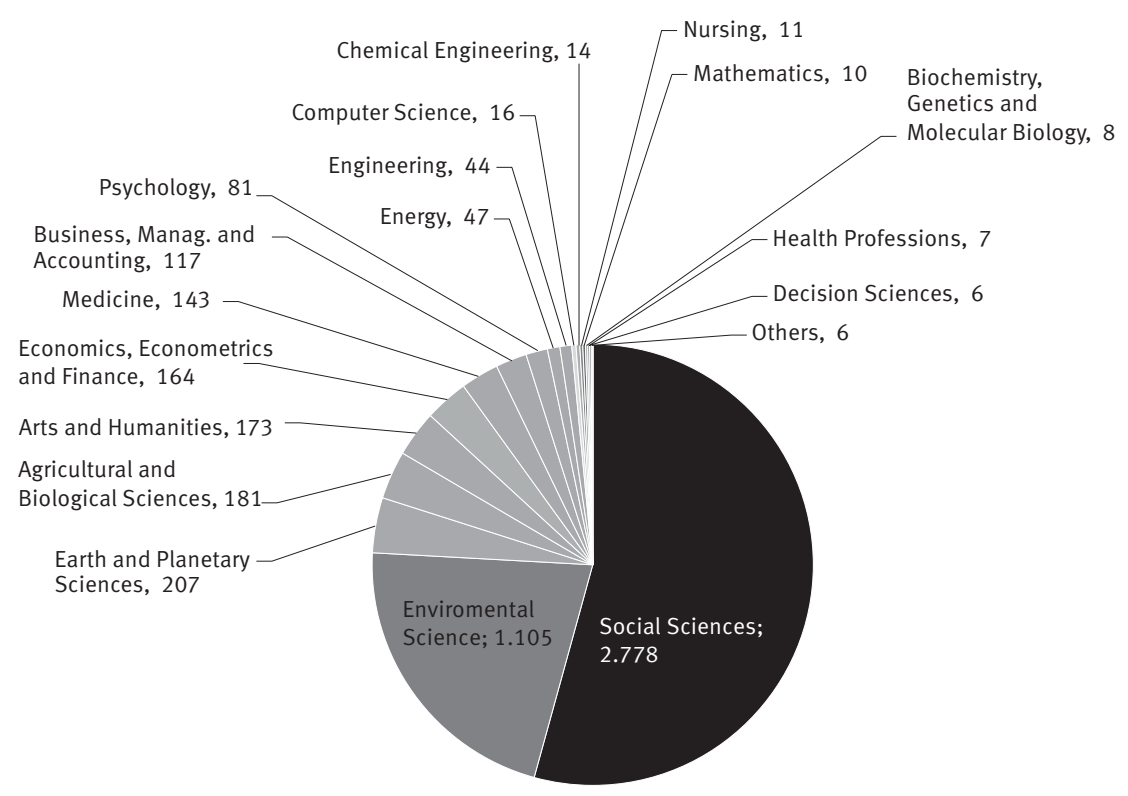

Fonte: Elsevier. Scopus. Disponível em 〈http://www.scopus.com/〉. Acesso em: 5 ago. 2015.

Nota: 2.788 artigos resultantes da consulta ((ALL("population and environment") OR ALL("população e ambiente")) AND PUBYEAR > 1995 AND (LIMIT-TO(DOCTYPE, “ar”)) AND (LIMIT-TO(SUBJAREA, “SOCI”).

Em B, um mesmo documento pode estar associado a mais de uma área. 
TABELA 1

Periódicos com maior número de artigos com o termo "População e Ambiente" 1996-2015

\begin{tabular}{|c|c|c|}
\hline Posição & Revista & Artigos \\
\hline 1 & Population and Environment & 390 \\
\hline 2 & Ecological Economics & 95 \\
\hline 3 & Environment and Behavior & 56 \\
\hline 4 & Applied Geography & 54 \\
\hline 5 & Global Environmental Change & 51 \\
\hline 6 & Ecology and Society & 40 \\
\hline 7 & Human Ecology & 39 \\
\hline 8 & Society and Natural Resources & 38 \\
\hline 9 & Energy Policy & 36 \\
\hline 10 & Journal of Environmental Management & 35 \\
\hline 11 & Environment and Planning A & 34 \\
\hline 12 & Land Use Policy & 33 \\
\hline 13 & Journal of Cleaner Production & 32 \\
\hline 14 & Population Space and Place & 31 \\
\hline 15 & Population Research and Policy Review & 31 \\
\hline 16 & Ecological Modelling & 31 \\
\hline 17 & Landscape and Urban Planning & 29 \\
\hline 18 & Geoforum & 26 \\
\hline 19 & Climatic Change & 25 \\
\hline 20 & Demography & 25 \\
\hline 21 & Environment Development and Sustainability & 25 \\
\hline 22 & Population Studies & 25 \\
\hline 23 & Agriculture Ecosystems and Environment & 24 \\
\hline 24 & Environmental Management & 24 \\
\hline 25 & World Development & 24 \\
\hline
\end{tabular}

Fonte: Elsevier. Scopus. Disponível em:〈http://www.scopus.com/〉. Acesso em: 5 ago. 2015

Nota: Seleção das 25 revistas com o maior número de artigos (1.253) dentre os 4.020 artigos científicos publicados desde 1996 que atendem ao critério de consulta ("população e ambiente” OR “population and environment”) AND ("social sciences” OR "environmental science").

Entre as principais palavras-chave empregadas nos artigos, destacam-se migration (internal e international), fertility, population growth, demography, population. De outra parte, sobressaem: climate change, sustainable development, sustainability, environment 
e land use change (e termos associáveis como deforestation e land cover change). As palavras-chave e os resumos dos artigos foram processados por meio do software NVIVO 10 para análises exploratórias de seus conteúdos, ficando evidente a variação de temas conforme o escopo de cada periódico selecionado.

Nas revistas de estudos populacionais e demografia, predominam seus temas típicos (migração, crescimento demográfico e fecundidade) e outros mais gerais das ciências sociais (desenvolvimento, sustentabilidade, consumo, produção, gerenciamento, planejamento, políticas). As questões ambientais aparecem geralmente subordinadas às discussões sociais-populacionais, com influências de outras tradições, como a ecologia humana, a economia regional, sociologia e antropologia.

Dentre os aspectos mais frequentes nestas revistas, destacam-se poluição, desmatamento e mudanças climáticas, em seus diversos aspectos. Por outro lado, nas revistas que não são de estudos de população, os temas ambientais anteriormente mencionados aparecem com preponderância sobre as questões demográficas.

Em relação aos procedimentos e fontes de dados, predominam as análises agregadas, "macro" ou regionais, com uso de fontes de dados censitários associadas a bases de dados ambientais, como as geradas por sensoriamento remoto. Em um subgrupo de artigos nota-se o uso de estratégias “micro", com estudos de caso que envolvem dados de campo coletados por unidades domésticas.

A recorrência de termos e temas e a presença de um grupo relativamente restrito de autores (156 pessoas são coautoras dos 2.788 artigos) indicam a existência de uma identidade, corpo ou campo, de pesquisa. Dada sua proeminência, a revista Poen é utilizada, a seguir, para um recorte que facilite a aproximação ao campo de P-A em termos de seus elementos mais centrais.

\section{Revista Population and Environment}

A revista foi criada em 1978 com o nome de Journal of Population, pela Human Sciences Press. Apesar da transformação das temáticas exploradas ao longo das décadas, a preocupação com uma proposta interdisciplinar já se apresentava desde o editorial do primeiro volume (THOMPSON, 1978). Atualmente, a referência à interdisciplinaridade e às temáticas ambientais é explícita: "The sole social science journal focused on interdisciplinary research on social demographic aspects of environmental issues" (SPRINGER, s.d.). Dentre as disciplinas principais figuram a demografia, a geografia, a sociologia e a antropologia, assim como a ecologia humana, a economia ambiental, a saúde pública e as ciências ambientais. Estabelecendo pontes entre elas, a revista se propõe a publicar pesquisas que contribuam para "new insights on the complex, reciprocal links between human populations and the natural environment", explorando métodos quantitativos, qualitativos e mistos (SPRINGER, s.d., grifo do autor). 
De acordo com a base de dados Web of Science, ${ }^{4}$ a revista tem dois domínios de pesquisa: demography; e environmental sciences and ecology. Pela análise exploratória de 526 artigos publicados entre 1990 e 2015, por meio do software NVIVO 10, percebem-se mudanças nas suas temáticas. A Figura 1, produzida a partir da frequência das palavras-chave nos artigos publicados no período, representa a mudança de tônica. Separando os artigos em três grupos segundo o ano de publicação - entre 1990 e 1999; entre 2000 e 2009; entre 2010 e 2015 -, a análise dos conteúdos revela que:

- diminuiu o uso de "growth" (crescimento populacional) e de termos associáveis às preocupações com a superpopulação (fertility, born...) e aumentou o emprego do termo "migration", sobretudo no período mais recente. A mudança reflete o redirecionamento de foco em determinados componentes da dinâmica demográfica, reforçando a crescente ênfase em mobilidade-migração-distribuição da população em estudos de P-A. Em contrapartida, o uso do termo “mortality” é bem menos frequente;

- cresceu a utilização do termo "environment(al)", sinal de que se explicita mais o termo "ambiente" em uma revista de estudos de população. Conforme o campo se fortalece, aumenta também o uso de "land" ("land use", "land use change") e de “climate”, principalmente no último período;

- os conceitos integradores, aqueles que expressam os esforços de relacionamento/ entendimento das interfaces População-Ambiente, variam em cada período: “capacity" (de carrying capacity) figura na lista de mais frequentes apenas no primeiro período; "sustentability", no segundo; e "vulnerability", no terceiro;

- outros termos, como “consumption" e "development”, aparecem com frequências bastante próximas nos três períodos. Figuram entre as temáticas que se mantêm ao longo do tempo, incluindo aquelas relacionadas aos efeitos do desenvolvimento sobre a saúde e bem-estar, urbanização e seus impactos, composição da população e mudanças ambientais.

A visão do conjunto de artigos mostra: recorrência de temas, questões e autores, indicativo de existência de compartilhamento de referenciais; e variações temáticas, ao longo do tempo, que são coerentes com a construção do campo de população e ambiente, ou seja, com a redução da ênfase em population growth e a progressiva crítica ao ponto de vista centrado na pressão do volume da população sobre recursos. Cabe estabelecer conexões com a trajetória do campo por meio de suas instituições e agentes, o que será apresentado a seguir pelo destaque ao quadro brasileiro em articulação ao internacional.

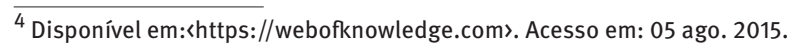




\section{FIGURA 1}

Palavras-chave em artigos da revista Population and Environment 1990-2015
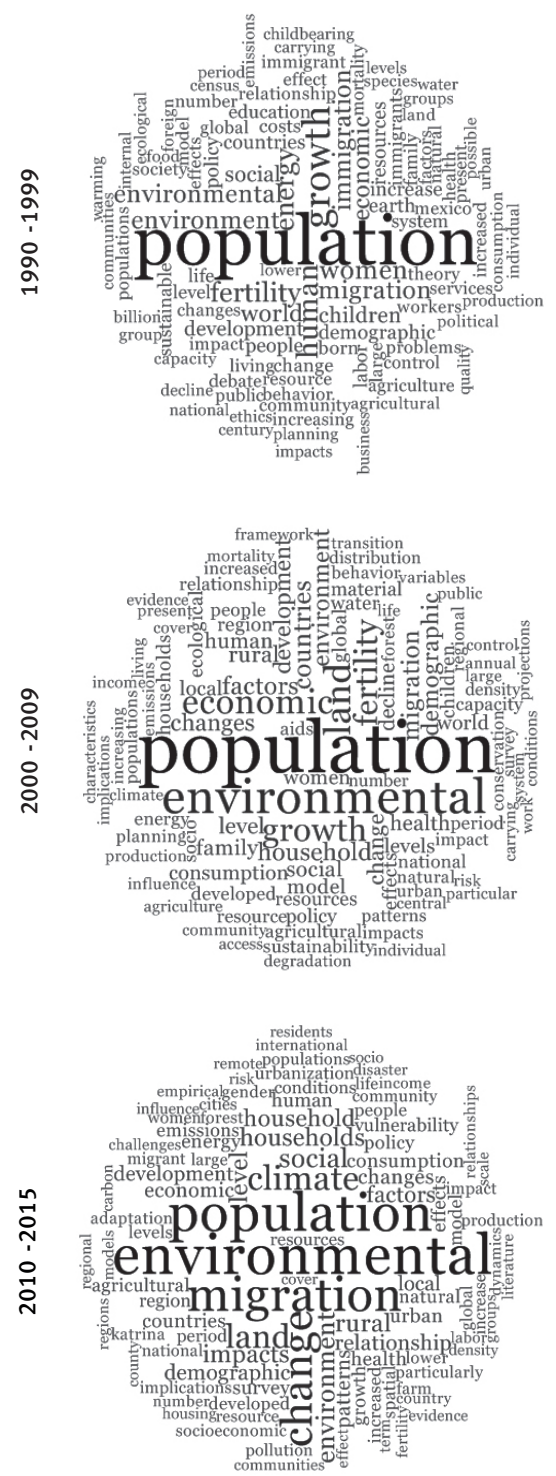

Fonte: Web of Science. Disponível em:〈https://webofknowledge.com〉. Acesso em: 05 ago. 2015.

Nota: Nuvem de palavras com base nas palavras-chave dos 526 artigos considerados. Figura processada pelo autor com o software NVIVO 10. Quanto maior o tamanho da fonte, mais frequente foi o uso do termo como palavra-chave.

\section{Como o campo se estrutura}

Ainda que a reflexão de População e Ambiente remeta à formulação malthusiana (MALTHUS,1798) e, consequentemente, aos primórdios da constituição da demografia e 
da economia, o campo de População e Ambiente se define nos anos 1980, se estrutura na década de 1990 para, em meados dos anos 2000, se expandir, conforme se pode observar pela análise das principais instâncias envolvidas no Brasil e no exterior.

No Brasil, a principal referência institucional é a Associação Brasileira de Estudos Populacionais (Abep) tanto por abrigar o Grupo de Trabalho “População, Espaço e Ambiente” (GT-PEA) quanto pela publicação da Revista Brasileira de Estudos de População (Rebep).

O GT-PEA foi criado no início da década de 1990 com o nome de "População e Meio Ambiente". A mudança de nome, nos anos 2000, denota a ampliação do grupo para além dos demógrafos e cientistas sociais e a preocupação de seus integrantes em incorporar o espaço nas suas discussões. A participação em um grupo de trabalho da Abep não é restrita aos associados, o que propicia um trânsito de pessoas externas que compartilham das temáticas de interesse de cada grupo.

A interação no GT-PEA se dá nas reuniões bianuais da Abep, em encontros específicos, em livros organizados e na coautoria de artigos em revistas científicas. Entre 1978-2006, na periodização proposta por Marandola Jr. e Hogan (2007), três fases expressam o processo de incorporação da temática de P-A ao corpo dos estudos de população: "vislumbres", entre 1978 e 1986; "precursores", nas reuniões de 1988 e de 1990; e "consolidação", entre 1992 e 2006.0 artigo distingue três conjuntos ("gerações") de autores no núcleo do campo no Brasil - mais ligados aos estudos de população -, além de um grupo de interlocutores e participantes ocasionais. ${ }^{5} \mathrm{~A}$ primeira geração é composta por fundadores da Abep, com centralidade no grupo desde a fase inicial (vislumbres). A segunda é composta por membros que atuaram no GT-PEA a partir da sua fase de consolidação. A terceira é formada por recém-doutores com envolvimento ativo com o grupo no início dos anos 2000.

Avançando na análise pela incorporação da atuação do GT-PEA nas reuniões da Abep no período subsequente, entre 2008 e 2014, pode-se dizer que tal se caracteriza como uma fase de expansão retroalimentada. A expansão que já se verificava ao final da etapa de consolidação se acelerou em termos de número de artigos, participantes e temas abordados, passando a se retroalimentar pela constante incorporação de recém-doutores orientados por participantes das fases anteriores. O Quadro 1 apresenta uma síntese dessa periodização.

Considerando apenas os eventos no século XXI, foram contabilizados 75 artigos ligados ao GT-PEA, entre 2000 e 2006, e 97, no período 2008-2014. 0 aumento no número de trabalhos carrega uma diversificação de temas, ênfases e autores, além da crescente incorporação das análises espaciais. A diversificação de conteúdos segue uma trajetória já em curso desde o início do GT-PEA, quando dois conjuntos de trabalhos se constituíram: de

\footnotetext{
${ }^{5}$ Para a seleção dos autores conforme as gerações, Marandola Jr. e Hogan (2007) levaram em conta a participação no GT-PEA, a pertinência e o reconhecimento do trabalho, a perspectiva demográfica adotada e a colaboração continuada. Autores que não atendiam aos quatro critérios foram classificados como interlocutores (pessoas que contribuem com o GT, mas sem uma atuação em demografia) ou como participantes ocasionais (aqueles que não estabeleceram colaboração ao longo do tempo).
} 
um lado, os estudos voltados para questões relativas à ocupação da fronteira Amazônica; e, de outro, aqueles focados nas condições de vida nas cidades.

QUADRO 1

Periodização do GT-PEA em encontros nacionais da Abep 1978-2014

\begin{tabular}{|c|c|c|}
\hline Período & Momentos e presença na Abep & Gerações de autores \\
\hline 1978-1986 & $\begin{array}{l}\text { Vislumbres } \\
\text { Temas ambientais estão presentes, embora } \\
\text { sem um corpo bem definido. }\end{array}$ & \multirow[t]{2}{*}{$\begin{array}{l}\text { Primeira - Fundadores da Abep } \\
\text { Daniel Hogan, Donald Sawyer, George Martine }\end{array}$} \\
\hline 1988-1990 & $\begin{array}{l}\text { Precursores } \\
\text { Trabalhos explicitam temas de P\&A. } \\
\text { A crescente identidade leva à criação do GT } \\
\text { "População e Meio Ambiente" }\end{array}$ & \\
\hline 1992-2006 & $\begin{array}{l}\text { Consolidação } \\
\text { Sessões específicas do GT passam a ser } \\
\text { organizadas. } \\
\text { Publicado o primeiro livro do grupo com } \\
\text { o título de População, meio ambiente e } \\
\text { desenvolvimento: verdades e contradições } \\
\text { (MARTINE, 1993a). }\end{array}$ & $\begin{array}{l}\text { Segunda - Membros que atuaram a partir da } \\
\text { fase de consolidação } \\
\text { Haroldo Torres, Heloisa Costa, John } \\
\text { Sydenstricker-Neto, Roberto Monte-Mór, } \\
\text { Roberto do Carmo } \\
\text { Terceira - Recém-doutores com envolvimento } \\
\text { ativo com o grupo nos anos } 2000 \\
\text { Alisson Barbieri, Álvaro D’Antona, Humberto } \\
\text { Prates da Fonseca Alves, Marley Vanice } \\
\text { Deschamps }\end{array}$ \\
\hline $2008-2014$ & $\begin{array}{l}\text { Expansão com retroalimentação } \\
\text { GT assume o novo nome (População, Espaço } \\
\text { e Ambiente), formalmente reconhecendo seu } \\
\text { maior escopo e a explícita incorporação das } \\
\text { análises espaciais. } \\
\text { Sessões de PEA buscam articulações com } \\
\text { sessões de outros GTs. }\end{array}$ & $\begin{array}{l}\text { Quarta - Recém-doutores formados pelas } \\
\text { gerações anteriores } \\
\text { Eduardo Marandola Jr., Ricardo Ojima, } \\
\text { Leonardo Freire de Mello, Cesar Marques, } \\
\text { Douglas Sathler dos Reis, Gilvan Guedes, } \\
\text { dentre outros. }\end{array}$ \\
\hline
\end{tabular}

Fonte: Entre 1978 e 2006 a periodização respeita a classificação de Marandola Jr. e Hogan (2007). 0 período 2008-2014 é caracterizado a partir dos programas das reuniões bianuais da Abep: XVI Encontro Nacional de Estudos Populacionais, em 2008 (disponível em 〈http://www.abep.org.br/?q=publicacoes/anais/anais-2008-popula\%C3\%A7\%C3\%A3o-espa\%C3\%A7oe-ambiente〉, acesso em 22 ago. 2015); XVII Encontro Nacional de Estudos Populacionais, em 2010 (disponível em <http:// www.abep.org.br/?q=publicacoes/anais-encontro-nacional-de-estudos-populacionais-2010>, acesso em 22 ago. 2015 ); XVIII Encontro Nacional de Estudos Populacionais, em 2012 (disponível em <http://www.abep.nepo.unicamp.br/xviii/anais/site/anais. php?id=0\#.VdiOBPZViko〉, acesso em 22 ago. 2015); e XIX Encontro Nacional de Estudos Populacionais, em 2014 (disponível em 〈http://abep.info/anais/index.php\#.Vdi1mfZViko〉, acesso em 22 ago. 2015).

Considerando os eventos da fase atual do GT-PEA, a partir de 2008, o Quadro 2 traz a relação das suas sessões. Em 2008, foram realizadas oito sessões do GT-PEA com incorporação de termos como vulnerabilidade, cultura, mudanças globais, além dos já consolidados relativos a saúde, desigualdades sociais e urbanização, e uma sessão metodológica específica sobre a dimensão espacial. Verifica-se a renovação das coordenações das sessões: duas, coordenadas por integrantes da segunda geração; todas as demais, por integrantes da terceira, da quarta e por interlocutores.

Em 2010, se deu a aproximação com outros grupos da Abep em sessões que buscaram maior interconexão de questões de P-A com temas normalmente tratados em sessões de outros GTs. Ocorreram três sessões sobre temas como as áreas de fronteira, metodologias, mobilidade e desenvolvimento sustentável coordenadas a uma perspectiva mais regional; outra, foi coordenada com uma sessão da demografia histórica. Em 2012, realizaram-se cinco sessões e, em 2014, oito. Discussões relacionadas aos desafios teóricos e metodológicos 
se somam aos temas recorrentes - tais como mobilidade, desigualdades socioambientais, território, fronteira - e a temas emergentes como as mudanças climáticas e o consumo.

0 crescimento do GT-PEA expressa-se na incorporação do termo "espaço" ao seu nome. A mudança, definida em 2006 e vigente na reunião de 2008, decorreu do interesse em atrair pesquisadores de outras disciplinas e para reconhecer a incorporação de análises espaciais - principalmente o uso das geotecnologias - por parte do grupo. Nesse movimento, registra-se a participação mais sistemática de pesquisadores inicialmente classificados como interlocutores, os quais passam a ser cada vez mais atuantes e reconhecidos como essenciais para as interfaces de P-A, como é o caso da atuação dos pesquisadores da Divisão de Processamento de Imagens (DPI) do Instituto Nacional de Pesquisas Espaciais (Inpe).

QUADRO 2

Sessões do GT-PEA em Encontros Nacionais da Abep

2008-2014

\begin{tabular}{|c|c|}
\hline Edição / Ano & Sessões do GT-PEA \\
\hline 2008 & $\begin{array}{l}07 \text { - População em risco e vulnerabilidade socioambiental; } 14 \text { - População, ambiente } \\
\text { e saúde; } 23 \text { e } 29 \text { - Urbanização e metropolização (I e II); } 30 \text { - Culturas, saberes e } \\
\text { territorialidades: população e articulações socioambientais; } 38 \text { - Abordagens metodológicas } \\
\text { integradas e novas metodologias; } 39 \text { - População, espaço e mudanças ambientais globais; } \\
46 \text { - Desigualdades socioespaciais e injustiças socioambientais. }\end{array}$ \\
\hline 2010 & $\begin{array}{l}\text { População e ambiente em áreas de fronteira; Aspectos teóricos e metodológicos no } \\
\text { estudo da relação população, espaço e ambiente; Mobilidade territorial e desenvolvimento } \\
\text { sustentável; Demografia do Nordeste: pensando os desafios atuais e futuros em população, } \\
\text { saúde e ambiente; População, espaço e ambiente desde uma perspectiva histórica. }\end{array}$ \\
\hline 2012 & $\begin{array}{l}03 \text { - Demografia espacial; } 12 \text { - Mobilidade, espaço e mudança ambiental: o desafio das } \\
\text { escalas; } 17 \text { - Desigualdades, conflitos socioambientais e desenvolvimento territorial; } 23 \\
\text { - População e fronteira: questões locais, desafios nacionais? } 36 \text { - Mudanças climáticas, } \\
\text { consumo e dinâmica demográfica: debates emergentes. }\end{array}$ \\
\hline 2014 & $\begin{array}{l}09 \text { - Questões sobre população e meio ambiente; } 12 \text { - Desigualdades, conflitos } \\
\text { socioambientais e a mobilidade espacial da população: aspectos demográficos na mudança } \\
\text { ambiental; } 22 \text { - Análise espacial e métodos de representação geocomputacionais em } \\
\text { estudos de população, espaço e ambiente: onde estamos e para onde vamos? } 31 \text { - } \\
\text { Urbanização, população e consumo: um eixo agregador para os estudos sobre população, } \\
\text { espaço e ambiente? } 39 \text { - Migração, mobilidade e redistribuição espacial da população no } \\
\text { Brasil: as velhas e as novas fronteiras (A); } 41 \text { - Dinâmica populacional, mudanças climáticas } \\
\text { globais e ambiente; } 45 \text { - As transições no Nordeste: população, espaço, economia e políticas } \\
\text { públicas; } 53 \text { - Para além das metrópoles: população, espaço e ambiente em pequenas e } \\
\text { médias cidades. }\end{array}$ \\
\hline
\end{tabular}

Fonte: Programas das reuniões bianuais da Abep: XVI Encontro Nacional de Estudos Populacionais, em 2008 (disponível em 〈http://www.abep.org.br/?q=publicacoes/anais/anais-2008-popula\%C3\%A7\%C3\%A3o-espa\%C3\%A7o-e-ambiente〉, acesso em 22 ago. 2015); XVII Encontro Nacional de Estudos Populacionais, em 2010 (disponível em <http://www.abep.org. $\mathrm{br} / ? \mathrm{q}=$ publicacoes/anais-encontro-nacional-de-estudos-populacionais-2010>, acesso em 22 ago. 2015); XVIII Encontro Nacional de Estudos Populacionais, em 2012 (disponível em <http://www.abep.nepo.unicamp.br/xviii/anais/site/anais.php?id=0\#. VdiOBPZViko〉, acesso em 22 ago. 2015); e XIX Encontro Nacional de Estudos Populacionais, em 2014 (disponível em <http://abep. info/anais/index.php\#.Vdi1mfZVikos, acesso em 22 ago. 2015).

Enquanto as três primeiras gerações de participantes foram responsáveis por capitanear a consolidação de um campo pela formação de massa crítica e definição de uma agenda com temas e enfoques próprios (MARANDOLA JR.;HOGAN, 2007), na atual fase de expansão retroalimentada novos doutores assumem posições de liderança na organização e produção científica ligada a temas que se desdobram dos iniciais.

Inicialmente, havia uma concentração de participantes-chave em instituições no Sudeste, na Universidade Estadual de Campinas (Unicamp) e na Universidade Federal de 
Minas Gerais (UFMG). No período mais recente, ainda que a centralidade se mantenha em instâncias como o Centro de Desenvolvimento e Planejamento Regional da UFMG (Cedeplar/ UFMG) e o Núcleo de Estudos de População “Elza Berquó” (Nepo/Unicamp), verifica-se a crescente atuação de pesquisadores ligados a novos programas e a outros centros de pesquisa, tais como: Escola Nacional de Ciências Estatísticas (Ence); Universidade Federal do Rio Grande do Norte (UFRN); Universidade Federal dos Vales do Jequitinhonha e Mucuri (UFVJM); Universidade Federal do ABC (UFABC); Universidade Federal de São Paulo (Unifesp); Instituto Brasileiro de Geografia e Estatística (IBGE) e o próprio Inpe.

Novas cohorts de pesquisadores foram incorporadas, dentre estas os recém-doutores em demografia orientados por participantes da segunda e da terceira gerações. Egressos dos primeiros programas de pós-graduação em demografia, agora profissionais em outras instituições em todo o país, favorecem a ampliação da área de cobertura institucional do GT-PEA e a identidade de um grupo multidisciplinar.

A articulação dos pesquisadores se manifesta em coletâneas emblemáticas da produção nacional em cada etapa - como Torres e Costa (2000), em que se constatam abordagens sobre capacidade de suporte, risco ambiental, urbanização e qualidade de vida; Hogan et al. (2002), também relevante por sua interface com a reflexão internacional, das grandes conferências; Martine (2012), em que se aborda a interação da dinâmica demográfica, desenvolvimento e mudanças ambientais, inclusive para um conjunto mais amplo de leitores; Guedes e Ojima (2012), uma sintética expressão dessa importante integração multidisciplinar e plurinstitucional, já no contexto da incorporação do componente espacial às discussões de população e ambiente - e em números especiais da Revista Brasileira de Estudos de População (v. 24, n. 2, de 2007; v. 32, n. 3, de 2015) e da Revista Espinhaço (v.3, de 2014).

\section{No contexto internacional}

A expansão do GT-PEA e do próprio campo de P-A no Brasil coincide com aquela verificada no contexto internacional, sobretudo em relação à International Union for the Scientific Study of Population (IUSSP), a Population Association of America (PAA) e a Asociación Latinoamericana de Población (Alap) - instâncias em que membros da comunidade brasileira se envolvem em distintos graus. Os eventos realizados pelas três organizações trazem sessões com temas de População e Ambiente, incluindo aqueles ligados à saúde e ao desenvolvimento. A Alap organiza eventos bianuais, com grande sobreposição à Abep por conta da participação da comunidade científica brasileira (integrantes do GT-PEA da Abep) na Red de Población y Medio Ambiente.

Sobre a constituição do campo e a atuação do conjunto de pesquisadores de P-A no âmbito internacional, cabe considerar as ações da IUSSP, o que inclui os seus eventos científicos e a criação do painel científico Population and Environment Research Network $(P E R N)$, um importante balizador do trabalho do grupo de cientistas interessados nos 
temas de população e ambiente. Com mais de dois mil membros de 135 países, o PERN é uma rede on-line gratuita, aberta aos interessados em temas de população e ambiente. ${ }^{6}$

Uma das iniciativas mais pertinentes para o entendimento do papel do PERN é a promoção de cyberseminars, seminários virtuais organizados por especialistas que apresentam textos para o debate. 0 primeiro deles, em 2001, revela o PERN como um balizador. 0 texto de referência, "The sustainable use of space: advancing the population/environment agenda", foi apresentado por George Martine, um dos fundadores do campo, com o propósito de orientar a agenda de pesquisa:

This pilot cyberseminar attempted to deal with some of the conceptual and practical issues involved in formulating a more meaningful population-environment agenda. Essentially, it asks - what can be done about environmental issues from a population perspective, in the framework of the new millenium? How and what can the knowledge, skills and tools of the population sciences effectively contribute to sustainability, via research, policy and action? It assumes that improving the relevance and specificity of the work on P-E linkages begins with a restatement of the problem; concurrently, these linkages have to be viewed more directly within the context of the prevailing development scenario (MARTINE, 2001, p. 1).

Desde então, os seminários refletem os temas candentes: desmatamento; consumo; poluição; expansão urbana; mobilidade da população (incluindo displacement); população-ambiente e desenvolvimento; mudanças climáticas. Ao mesmo tempo que refletem o que vem sendo pensado e produzido, os cyberseminars apontam caminhos e acabam contribuindo para uma certa coesão, com uma agenda peculiar e o interesse em $P$-E linkages.

Tal agenda se reflete na Conferência Internacional de População da IUSSP. Pela análise de seus programas, $\mathrm{P}$-A tem presença constante nas sessões, inclusive com atuação dos autores internacionais reconhecidos como referências do campo. Ainda que se note o predomínio numérico de autores de língua inglesa, os eventos provocam um diálogo bastante amplo, com autores de países de várias partes do mundo, o que é facilitado pela abertura que a IUSSP dá para sessões regionais, a cada evento.

No Quadro 3, a lista das sessões ligadas aos temas de população e ambiente nos eventos da IUSSP, entre 1997 e 2013, revela a abrangência dos temas considerados em relação aos componentes da dinâmica demográfica. As sessões reúnem estudos de várias partes do mundo com distintas preocupações de P-A, incluindo saúde, composição, crescimento e densidade populacionais. Aparecem também os grandes temas e problemas ambientais globais, como mudanças climáticas e mudanças na cobertura da terra, incluindo emissões de dióxido de carbono, consumo de energia, elevação do nível do mar, desertificação, gerenciamento de áreas protegidas, recursos hídricos e urbanização. ${ }^{7}$

\footnotetext{
${ }^{6}$ Criada por iniciativa da IUSSP, atualmente é gerenciada pelo Center for International Earth Science Information Network (Ciesin) da Columbia University, recebe apoio do Future Earth - da National Aeronautics and Space Administration (Nasa) - e do Socioeconomic Data and Applications Center (Sedac).

${ }^{7}$ Não se pode ignorar, no plano mais geral, a importância da IUSSP no grande e polarizado debate sobre população, desenvolvimento e ambiente, como o que se pode observar na conferência em Beijing, desde a sua primeira sessão plenária fomentada por reflexões como a de Caldwell (1997) sobre a transição na fecundidade.
} 
QUADRO 3

Sessões de População e Ambiente em conferências da IUSSP 1997-2013

\begin{tabular}{|c|c|}
\hline Evento & Sessões / Temas de População e Ambiente \\
\hline Beijing, 1997 & $\begin{array}{l}\text { I05 - Population, environment and sustainability } \\
\text { Temas: micro-level analysis of environmental impact; interactive systems models; CO2; } \\
\text { land-use change; migration; sustainability }\end{array}$ \\
\hline Salvador, 2001 & $\begin{array}{l}\text { Duas sessões claramente de P\&A: S08 Demographic dynamics and environmental change } \\
\text { at the local level; S09 Population and environment } \\
\text { Duas outras sessões com temas pertinentes: S67 Demographic dimensions of land use and } \\
\text { land cover change e S68 Population applications of spatial analysis system (SIS) }\end{array}$ \\
\hline Tours, 2005 & $\begin{array}{l}\text { Tópico } 9 \text { (Environment, biology and genetics), com várias sessões } \\
6 \text { - Environment, climate and population; } 19 \text { - Paleodemography; } 56 \text { - Contribution of } \\
\text { genealogies to historical demography and population genetics; } 57 \text { - Climate, population, } \\
\text { and health; } 72 \text { - Population and environment linkages in developing countries; } \\
94 \text { - Interpretations of population history; } 123 \text { - Evolutionary ecology, kinship and } \\
\text { reproduction; } 137 \text { - Urbanization, environment and development; } 162 \text { - Population and } \\
\text { environment; } 171 \text { - Population, environment and development; } 185 \text { - Migration and the } \\
\text { environment }\end{array}$ \\
\hline Marrakech, 2009 & $\begin{array}{l}\text { Tópico } 12 \text { Environment } \\
29 \text { - Water and population: impact on health and mobility; } 74 \text { - Population impact } \\
\text { on deforestation in developing countries; } 97 \text { - Population distribution processes and } \\
\text { environmental change; } 108 \text { - Environment-induced migrants (1); } 151 \text { - Population and } \\
\text { environment: local and regional planning challenges; } 162 \text { - Population pressure, resource } \\
\text { use and environmental degradation; } 170 \text { - Interrelations between population and climate } \\
\text { change; } 181 \text { - Population and climate change (IUSSP Plenary); } 191 \text { - Environment and } \\
\text { mobility; } 207 \text { - Environment and health; } 224 \text { - Environment-induced migrants (2) }\end{array}$ \\
\hline Busan, 2013 & $\begin{array}{l}\text { Nove sessões com temas de População e Ambiente } \\
\text { 025 - Population dynamics and climate change; } 146 \text { - Population, environment, health, } \\
\text { and development in Africa; } 224 \text { - Population dynamics and environmental linkages; } \\
262 \text { - Impacts of environmental and climate change on health and mortality; } 276 \text { - Fertility } \\
\text { and reproductive health: examining links with the environment; } 277 \text { - Risk mapping; } \\
284 \text { - Population and the environment; } 291 \text { - Population-Environment dynamics in Latin } \\
\text { America; } 306 \text { - Migration as a mode of adaptation to extreme climate events, natural } \\
\text { disasters and environmental change }\end{array}$ \\
\hline
\end{tabular}

Fonte: Programas das reuniões da IUSSP: Beijing, 1997 (disponível em <http://archive.iussp.org/Activities/gcp-beijing/beijingprog.php〉, acesso em 23 ago.2015); Bahia, 2001 (disponível em 〈http://archive.iussp.org/Brazil2001/programme.php〉, acesso em 23 ago.2015); Tours, 2005 (disponível em 〈http://iussp2005.princeton.edu/〉, acesso em 23 ago.2015); Marrakech, 2009 (disponivel em 〈http://iussp2009.princeton.edu/〉, acesso em 23 ago.2015); Busan, 2013 (disponível em <http://iussp.org/sites/ default/files/Conference\%20Programme.pdf), acesso em 23 ago.2015).

Em larga medida, são percebidas correspondências temáticas entre as sessões da IUSSP e as da Abep, principalmente nos aspectos relacionados com a mobilidade e redistribuição da população. Apesar de diferenças de ênfases em questões e abordagens preponderantes no contexto nacional, existe articulação na agenda nacional com as discussões internacionais, posto que a atuação do grupo de P-A no Brasil, desde o seu início, se dá com estreito diálogo internacional. As histórias da construção do campo, aqui e lá, se intercruzam.

Tais grupos e seus eventos podem ser entendidos como uma espinha dorsal do campo. Suas ações se colocam em um contexto geopolítico-institucional mais amplo, que se expressa no conjunto das Conferências de População e nas Conferências de Meio Ambiente da ONU e remetem ao debate sobre População, Desenvolvimento e Ambiente, em larga medida pautado por embates entre "otimistas" e "pessimistas" (HIRSCHMAN, 2004, 
p. 11). As visões antagônicas das relações entre população e ambiente e entre população e desenvolvimento alimentaram o grande volume de publicações científicas entre as décadas de 1970 e 1990, bem como as disputas político-ideológicas verificadas nas grandes conferências da ONU, desde então.

\section{Entre as conferências de população, desenvolvimento e ambiente}

O trabalho de Coale e Hoover (1958) foi um marco ao relacionar o rápido crescimento demográfico e a escassez de recursos naturais como obstáculos ao desenvolvimento econômico. 0 medo de uma explosão populacional foi alardeado no livro The population bomb (EHRLICH, 1968), o qual ajudou a propagar a crença em uma iminente falta de alimentos causada pela superpopulação do planeta. Posteriormente, o Relatório Meadows, Limits to Growth, do Clube de Roma (RANDERS; MEADOWS, 1975), concluiu que seria necessário diminuir o crescimento demográfico e conter a expansão da economia para evitar a desorganização socioeconômica e o aumento da mortalidade.

0 postulado foi oficialmente rebatido no Relatório da National Academy of Sciences (NAS) (1986), o qual relativizou a causalidade entre crescimento populacional e não desenvolvimento, incluindo na análise fatores socioeconômicos, políticos e institucionais que podem comprometer o desenvolvimento e afetar os recursos naturais (HOGAN, 2000). ${ }^{8}$

A emergência de uma visão de P-A menos dicotômica não pode ser dissociada do entrelaçamento das agendas das grandes conferências internacionais da ONU, sobretudo pela construção e usos da noção de desenvolvimento sustentável, um evidente ponto de contato de autores em distintas frentes disciplinares e de ambientalistas (HOGAN; VIEIRA, 1992; VIOLA; LEIS, 1992). ${ }^{9}$

0 entrelaçamento das preocupações que foram se sucedendo nos debates travados nas Conferências de População e nas Conferências de Meio Ambiente, entre as décadas de 1970 e 1990, passa pelas discussões sobre problemas ambientais globais, como os gases de efeito estufa e o aquecimento global, e pelas antagônicas posições quanto às políticas controlistas. Os grandes debates imbricam-se, ao longo do tempo, na chave de População, Desenvolvimento e Ambiente e se relacionam a componentes essenciais para a identidade do campo de P-A nos anos 1990 - como o enfrentamento ao mito malthusiano. Segue uma breve descrição de aspectos das conferências, chamando a atenção para elementos desse imbricamento de agendas. ${ }^{10}$

\footnotetext{
${ }^{8}$ Sobre a contextualização e a relação entre crescimento populacional e desenvolvimento econômico no período, ver Birdsall (1977); Hogan (1989); Keyfitz (1996); Stonich (1989). Para uma revisão da relação entre população e desenvolvimento, ver Rios-Neto (2009).

${ }^{9}$ De acordo com a definição mais difundida, é preciso que o crescimento econômico coexista com conservação de recursos naturais numa perspectiva intergeracional. 0 desenvolvimento deve ser capaz de atender às necessidades das gerações contemporâneas sem o comprometimento da capacidade das futuras atenderem às suas próprias necessidades (CMMD, 1988).

${ }^{10}$ Para uma exposição mais detalhada das agendas e conferências, ver, entre outros, Alves (2014); Hogan, Berquó e Costa (2002); Mello e Hogan (2006).
} 


\section{Até a Eco-92}

As questões de população possuem um papel de destaque na agenda das Nações Unidas, criada em 1945. Um ano após sua fundação, a instituição já contava com uma Comissão de População, a qual veio a definir uma Divisão de População (BERQUÓ, 2014, p. 17). Pensando sobre o quadro de população e desenvolvimento, e ainda de acordo com Berquó (2014, p. 17), desde 1948, o Demographic Year Book “tornou-se peça central de referência”.

A importância das temáticas populacionais na discussão sobre desenvolvimento aparece desde as primeiras conferências com presença da ONU: a World Population Conference (Conferência Mundial de População), em Roma (1954) e em Belgrado (1965), esta última organizada pela IUSSP. As tensões decorrentes das distintas visões sobre o papel do volume da população para o desenvolvimento e a pobreza se evidenciam nas duas reuniões subsequentes, nas quais o debate ideológico quanto ao papel da população foi intenso e dinâmico.

Na terceira World Population Conference, em Bucareste, 1974, a redução da fecundidade aparecia como condição para o desenvolvimento econômico.

Dividida entre os "controlistas" e os "desenvolvimentistas", os países mais ricos defendiam a concepção neomalthusiana de reduzir a fecundidade para promover o desenvolvimento e a erradicação da pobreza. Mas a União Soviética e os países do Terceiro Mundo, liderados pela China e pela Índia, defendiam a prioridade do fortalecimento das políticas de apoio ao desenvolvimento em contraposição ao controle da natalidade e ao planejamento familiar. Venceram os segundos, com o bordão símbolo de Bucareste: "0 desenvolvimento é o melhor contraceptivo" (ALVES, 2014, p. 222).

Na International Conference on Population, no México, 1984, ainda se destacava a preocupação com os problemas do crescimento demográfico. Porém, "houve uma surpreendente reconfiguração do jogo de forças políticas", uma vez que a China passou a adotar a política de filho único ("a política neomalthusiana mais draconiana da história”), no final da década de 1970, enquanto os EUA, sob o governo Reagan, "abandonaram a defesa do controle da natalidade e passaram a defender o laissez-faire populacional” (ALVES, 2014, p. 222).

Do lado ambiental, a United Nations Conference on the Human Environment (Conferência das Nações Unidas sobre Meio Ambiente Humano), em Estocolmo,1972, colocou as necessidades de desenvolvimento no debate sobre o meio ambiente global. Na ocasião, foi criado o Programa das Nações Unidas para o Meio Ambiente (Pnuma). Em 1982, em Nairóbi, houve novo encontro e o compromisso de criação da Comissão Mundial de Meio Ambiente e Desenvolvimento (CMMD), implementada no ano seguinte. 0 relatório Nosso futuro comum (Relatório Brundtland), publicado em 1987, foi produzido pela CMMD (1988) e definiu o "desenvolvimento sustentável" do modo como ficou mais conhecido.

Dois outros eventos com o apoio das Nações Unidas devem ser mencionados, na virada dos anos 1980 para os 1990, principalmente pela emergência da temática das mudanças climáticas. A International Conference of the Changing Atmosphere, em Toronto, 1988, constituiu o Painel Intergovernamental sobre Mudanças Climáticas (IPCC); a Conferência 
de Genebra, 1990, discutiu um tratado internacional do clima, o qual foi criado dois anos depois e constituiu o Comitê Intergovernamental de Negociação para uma Convenção-Quadro sobre Mudanças Climáticas.

A integração das duas agendas, construídas em frentes distintas, fica mais evidente a partir da conferência realizada em 1992, no Rio de Janeiro.

\section{A partir da Eco-92}

A United Nations Conference on Environment and Development (Conferência das Nações Unidas para o Meio Ambiente e o Desenvolvimento), Rio-92 ou Eco-92, gerou a Agenda 21, a Convenção da Biodiversidade e a Convenção-Quadro das Nações Unidas sobre o Meio Ambiente - responsável por organizar conferências anuais (Conference of the Parties-COP) com foco nas questões climáticas, a partir de 1995 (BODANSKY, 2001).

Com a Agenda 21, a ponte população e ambiente, balizada pelo desenvolvimento sustentável, se faz evidente. Especificamente no capítulo 5, "Dinâmica demográfica e sustentabilidade”, fatores demográficos são colocados programaticamente:

5.1. Este capítulo contém as seguintes áreas de programas:

(a) Desenvolvimento e difusão de conhecimentos sobre os vínculos entre tendências e fatores demográficos e desenvolvimento sustentável;

(b) Formulação de políticas nacionais integradas para meio ambiente e desenvolvimento, levando em conta tendências e fatores demográficos;

(c) Implementação de programas integrados de meio ambiente e desenvolvimento no plano local, levando em conta tendências e fatores demográficos (CNUMAD, 1995, p. 40).

De outra parte, na International Conference on Population and Development, no Cairo, 1994, ampliou-se o debate dos problemas de população com o entendimento de que as políticas populacionais devem ir além do planejamento familiar, incluindo desenvolvimento social, saúde, direitos humanos e reprodutivos (ASHFORD, 2014; ALVES, 2014). Sob a ótica do desenvolvimento sustentável, os problemas da desigualdade e pobreza, dos padrões de consumo da sociedade e dos níveis de vida mínimos foram tomados como parte da reflexão quantitativa e qualitativa sobre degradação ambiental (LASSONDE, 1996). O Programme of Action of the International Conference on Population and Development (PoA), adotado por 179 países para um período de 20 anos (UN, 2014), deixa evidente as relações entre população, desenvolvimento e bem-estar.

O entrelaçamento de agendas dos dois conjuntos de discussões - nas de população e nas de ambiente - está evidente no capítulo III do documento produzido na reunião de 1994, "Inter-relações entre população, crescimento econômico sustentado e desenvolvimento sustentável”, no qual se explicitam as inter-relação da mudança de população, uso de recursos (consumo), meio ambiente e desenvolvimento (UN, 1994,cap. III - A):

Há um consenso geral de que a pobreza generalizada e persistente e graves injustiças sociais e em razão do sexo têm significativa influência nos parâmetros demográficos 
como crescimento, estrutura e distribuição da população e, por sua vez, são por eles influenciadas. Há também um consenso geral de que sistemas insustentáveis de consumo e produção estão contribuindo para o uso insustentável de recursos naturais e para a degradação ambiental assim como para o aumento das injustiças sociais e da pobreza com as consequências, acima mencionadas, para parâmetros demográficos. A Declaração do Rio sobre Meio Ambiente e Desenvolvimento e a Agenda 21, aprovadas pela comunidade internacional na Conferência das Nações Unidas sobre Meio Ambiente e Desenvolvimento, apelam por sistemas de desenvolvimento que reflitam a nova compreensão destas e outras articulações intersetoriais.

A aproximação avançou em oportunidades que se seguiram ao Cairo-1994, como nas sessões especiais (Special Session of the United Nations General Assembly) em 1999, 2004 e 2014 - especialmente no documento Framework of Actions (UN, 2014b).

Dando sequência à sucessão de referências cruzadas entre conferências de população e conferências de meio ambiente, em 2002, em Johannesburg, ocorreu a World Summit on Sustainable Development (WSSD). A reunião, conhecida como Rio+10, retomou a discussão do tema do desenvolvimento sustentável. Em 2012, no Rio de Janeiro, ocorreu a United Nations Conference on Sustainable Development (Rio+20). Do documento final, The future we want, alguns postulados e recomendações merecem aqui destaque, uma vez que reconhecem a necessidade de erradicação da pobreza e da fome, bem como as conexões entre aspectos econômicos, sociais e ambientais.

2. Eradicating poverty is the greatest global challenge facing the world today and an indispensable requirement for sustainable development. In this regard, we are committed to freeing humanity from poverty and hunger as a matter of urgency.

3. We therefore acknowledge the need to further mainstream sustainable development at all levels, integrating economic, social and environmental aspects and recognizing their interlinkages, so as to achieve sustainable development in all its dimensions (UN, 2012, p. 1-2).

Em Renewing political commitment, do mesmo documento, são também retomados princípios da Eco-92 e de outras reuniões. 0 parágrafo 16 é especialmente relevante, pois, em sua parte final, se compromete com princípios das Conferências de População (o PoA), selando o entrelaçamento de agendas (UN, 2012, p. 3-4):

16. We reaffirm our commitment to fully implement the Rio Declaration on Environment and Development, Agenda 21 [...] the Millennium Development Goals, the Programme of Action of the International Conference on Population and Development, the key actions for the further implementation of the Programme of Action of the International Conference on Population and Development and the Beijing Declaration and Platform for Action.

\section{Reflexos no campo de P-A}

As conferências da ONU foram importantes para o campo de P-A pela aproximação de duas grandes agendas, que constituíram o foco em P-E linkages no tratamento de questões 
de população, desenvolvimento e ambiente. Também influenciaram nos eixos e preocupações de encontros acadêmicos e em artigos científicos, os quais foram se modificando ao longo do tempo - por exemplo, os problemas no meio urbano, as mudanças na cobertura da terra, as mudanças climáticas, o consumo.

Nos anos 1980, as reflexões dos autores considerados os precursores do campo de População e Ambiente no Brasil - Martine, Sawyer e Hogan, todos os três com grande trânsito internacional - partiam do quadro das discussões sobre população e desenvolvimento (SAWYER, 1993), o qual conduzia aos problemas ambientais. Ao se posicionarem contrários à visão centrada na determinação do volume (e do crescimento) populacional sobre os problemas ambientais, as condições de vida e a pobreza, estes autores deslocaram a produção acadêmica para outros elementos da dinâmica demográfica, para a redistribuição espacial da população e para as relações recíprocas de população e ambiente.

A partir de tais deslocamentos, eles estabeleceram diálogos com as outras ciências sociais (HOGAN; VIEIRA, 1992; HOGAN, 1993) e com as ciências ambientais (por exemplo, PHILIPPI JR. et al., 2000). No caso das ciências sociais, não se pode ignorar a relação com a sociologia ambiental, a qual remete a discussões mais amplas sobre sociedade de risco (BECK, 1992), que veio a ser, posteriormente, uma das influências para os estudos sobre vulnerabilidade. Nos anos 1980-90, os principais trabalhos incluíam os referenciais de capacidade de suporte, sustentabilidade e desenvolvimento sustentável; nas décadas seguintes, incorporaram-se os de vulnerabilidade e risco. Na busca por caminhos eficientes para romper com a dicotomia população versus ambiente, gestou-se um campo interdisciplinar.

Tais diálogos foram orientados, principalmente, para os problemas no meio urbano. Para Martine (1991, 1993), a redistribuição da população no espaço é a variável demográfica mais relevante para a definição da agenda ambiental. Com a concentração da população em cidades e as desigualdades ali presentes, o urbano e a "agenda marrom" estavam no foco das atenções. No contexto urbano, a desigualdade social e a pobreza se confundem com a degradação ambiental: "As cidades mais degradadas, e os distritos mais degradados destas cidades, são ocupadas pelos mais pobres dos pobres, agregando-se um fator ambiental ao peso da desigualdade social" (HOGAN, 1993, p. 73).

Acompanhando o grande debate internacional, a lente da demografia captava as transformações pelas quais o país vinha passando. A transição demográfica (KIRK, 1996; LESTHAEGHE, 2010) no Brasil contribuiu para a relativização do peso do crescimento vegetativo nas construções dos problemas ambientais (MARTINE et al., 1993c), com reflexos ainda no pensamento atual. Seus efeitos na estrutura etária, sobretudo o aumento do peso relativo dos idosos na população total (CARVALHO; GARCIA, 2003), justificaram outras ênfases como, por exemplo, em estudos dos efeitos do envelhecimento da população sobre o consumo e sobre as emissões de $\mathrm{CO}_{2}$ (O’NEILL et al., 2010). A associação da transição demográfica aos processos de redistribuição espacial da população em cidades (transição urbana) ajuda a entender a ênfase dada aos problemas ambientais urbanos ontem e hoje (CARMO; D’ANTONA, 2011). O fenômeno da urbanização atual recoloca em estudos mais 
recentes (OJIMA; HOGAN, 2009) a preocupação com a relação entre desigualdade social e problemas ambientais, já apontada na década de 1990 (HOGAN,1993; MARTINE, 1993a).

Além das questões e problemas urbanos, nos anos 1980-1990, pesquisas na Amazônia constituíram-se em uma outra frente importante no quadro aqui apresentado, tendo em vista as preocupações globais em relação ao desmatamento de florestas equatoriais. Sob várias óticas, trabalhos como os de lanni (1979a, 1979b) e Martins (1989), da sociologia, Muller (1992), da economia, Becker (1990), da geografia, Sawyer (1983, 1984, 1987) e Martine (1992), da demografia, oferecem análises marcantes sobre o modelo de desenvolvimento na expansão da "fronteira" e os efeitos dos surtos e frentes de ocupação da região.

As pesquisas das ciências sociais se justapõem ao conjunto de trabalhos sobre a perda da cobertura florestal e da biodiversidade - por exemplo, Fearnside (1991, 1993a, 1993b). ${ }^{11}$ Levantamentos com base em sensoriamento remoto, como os da Nasa e do Inpe, davam cores e formas para o desmatamento e alimentavam estudos que estabeleciam relações entre população e redução de recursos florestais (FAO, 1993, 1995, 1996, 1998). De uma outra perspectiva, nos anos 1990, floresceram trabalhos empíricos focados em unidades domésticas em lotes agropecuários. Essa linha de atuação teve também grande impacto na produção internacional e brasileira dos anos 2000, constituindo-se em um relevante caso para a percepção da complexidade dos objetos do campo de P-A (CÔRTES; D’ANTONA, 2014). ${ }^{12}$

Reflexo do amplo quadro de População-Desenvolvimento-Ambiente, assim chegou o campo de P-A ao século XXI: emergente e marcadamente interdisciplinar; focado em relações recíprocas (interfaces de população e ambiente) e predisposto ao abandono do mito malthusiano. Partindo da matriz disciplinar de estudos populacionais, os fundadores de P-A acabaram por criar condições para a produção de um conhecimento que escapa da referida matriz.

\section{A insubordinação de um campo interdisciplinar}

A constituição do campo interdisciplinar de P-A opera entre dois mitos. 0 primeiro remete a Malthus e à associação entre pobreza e superpopulação, estando na base da discussão de População e Desenvolvimento a partir da demografia e das suas interfaces com a economia, ciência com a qual compartilha o mito (OLIVEIRA, 1985). Séculos depois, encontra-se na gênese do campo de População e Ambiente, uma vez que a preocupação com o volume populacional passa a incorporar a temática ambiental na tríade População, Desenvolvimento e Ambiente, indicação que superpopulação, pobreza e subdesenvolvimento devem ser associados aos problemas ambientais do século XX. Reativamente ao

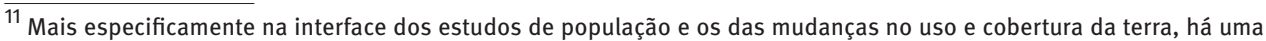
robusta produção internacional, interdisciplinar, como se pode notar, por exemplo, no conjunto dos textos publicados pelo National Research Council (2005).

${ }^{12}$ Ver, dentre outros, Bilsborrow (1987), Bilsborrow e Geores (1994), Walker e Homma (1996), Pichón (1997), Marquete (1998), McCracken et al. (2002) e Pan (2003).
} 
mito, trabalhos com os de Hogan $(1991,1992)$ evidenciam a construção teórico-empírica que passa a considerar o volume da população um fator agravante de problemas ambientais e não uma variável determinante. ${ }^{13}$

O segundo mito, o das relações recíprocas, decorre do reconhecimento de efeitos entre as variáveis “demográficas" e as "ambientais”. Quase um lema - mesmo que sem o mesmo peso do primeiro mito -, é um importante marco de oposição ao ideário neomalthusiano e à centralidade atribuída ao volume populacional. Como a síntese de um grande desafio conceitual, metodológico e identitário, motiva buscar uma perspectiva integradora e voltada para a relação entre os termos "P" e " $A$ " em lugar dos olhares unidirecionais, voltados ora para os efeitos da dinâmica populacional sobre o ambiente, ora para os impactos das mudanças ambientais sobre a população (LUTZ; PRSKAWETZ; SANDERSON, 2002; MARANDOLA JR.; HOGAN, 2007).

Contudo, a ênfase em outras formas de ver os fenômenos acaba por gerar uma tensão disciplinar com a própria demografia. Enquanto o primeiro mito tem origem e crítica identificáveis no âmbito da disciplina, o segundo parece não se conformar a limites disciplinares.

A insubordinação do campo de P-A em relação a determinados limites da demografia se acelera nos anos 1990. As motivações são de várias ordens entrelaçadas e, em larga medida, decorrentes dos tipos de problemas de interesse:

[...] the population-environment nexus is inherently multidisciplinary, which makes it more difficult to achieve theoretical advances or even to conduct empirical research which all can accept as valid (BREMMENER; BILSBORROW, 2005, p. 4).

O reconhecimento da reciprocidade das interferências de "P" e de "A" influencia vários dos populacion and enviroment frameworks nos anos 1990 (HUNTER, 2000; LUTZ, 1994; NESS, 1994) e marca a incorporação de mais elementos, dimensões e escalas. Segundo Bremmener e Bilsborrow (2005, p.4):

The initial scholarly debate as well as the popular media's depiction of population-environment relationships focused on one aspect of demography (population growth) and its relationship to the environment and development. More recent research, however, has begun to deal with additional dimensions of demography, including population mobility (in-migration, out-migration, urbanization, temporary migration, and even international migration), age and sex composition, and mortality and morbidity. In addition, there is growing research at multiple scales which is finding that the relationships between demographic aspects and the environment may differ at different scales (individual, household, community, regional, and global).

Apesar do caráter multidisciplinar de um campo sujeito a distintas influências teóricas e metodológicas, constitui-se um corpo em que se pode identificar a crescente importância da complexidade (HUMMEL et al., 2013). 0 novo mito complexifica as questões ambientais,

\footnotetext{
13 Ao abordar as condições institucionais para "o desenvolvimento de estudos ambientais na demografia brasileira", George Martine declara que a oposição ao neomalthusianismo "pode ser vista em retrospecto como corajosa ou irônica, tendo em vista que este tinha sido responsável, em parte, pelo próprio florescimento da demografia no Brasil” (CARMO; JOHANSEN, 2015, p. 296-297).
} 
torna o campo fortemente interdisciplinar e, cada vez mais, aparentemente deslocado de um arcabouço disciplinar. Conforme P-A traz para si os efeitos dos diálogos com as ciências sociais e as ambientais, crescentemente são incorporados elementos que criam um estranhamento epistemológico em relação à demografia. Isso se manifesta também com o reconhecimento das dificuldades teórico-epistemológicas e empíricas pelos autores do campo (LUTZ; PRSKAWETZ; SANDERSON, 2002; BREMMENER; BILSBORROW, 2005).

Por outro lado, existe a demanda por uma discussão epistemológica que, de certo modo, recupere a centralidade de questões demográficas. As tensões constitutivas do campo motivam considerações sobre a necessidade de uma concepção (MARANDOLA JR.; HOGAN, 2007), ou de um paradigma (LEFF, 1993), para uma demografia ambiental. Se, no início dos anos 1990, Hogan (1991) fazia a crítica à demografia enquanto se constituía uma base de P-A, o amadurecimento do campo até os anos 2000 fez ver que se faz necessário "an entirely new approach to the field", uma nova demografia ambiental (HOGAN, 2001).

Alguns esforços para a retomada de uma matriz conceitual e instrumental de caráter disciplinar mais próximo (ou reconhecível como) da demografia tem se dado especialmente por meio do que se se intitula como demografia ambiental. A própria denominação "demografia ambiental" pode ser vista como uma forma de incorporação - ou de subordinação - de parte dos avanços de P-A à disciplina de origem. Outra subdisciplina que pode servir a essa subordinação é a demografia espacial (CASTRO, 2007; VOSS, 2007), a qual pode ser vista como uma via de aproximação das questões de P-A a uma demografia formal, das estatísticas espaciais, que pode facilitar o diálogo com as ciências ambientais, no contexto do big data.

Sociedade-ambiente, cultura-natureza, população-ambiente são expressões relacionáveis a tensões que parecem ser próprias das disciplinas, subdisciplinas ou campos que enveredam por interfaces que transgridam fronteiras disciplinares claras, seja na sociologia, na economia, na antropologia ou na demografia. Portanto, na problematização das "relações recíprocas" no âmbito da demografia, ecoam influências e desafios à coesão - e/ou adequação disciplinar - que aparecem em outras tradições que não resolveram, necessariamente, suas próprias insubordinações.

Sobre a construção aqui proposta, resta considerar que o mito das relações recíprocas se ofereceu como uma alternativa ao mito anterior, mas não o suprimiu. Os esforços interdisciplinares integradores, essenciais para a conformação do segundo mito e para as tensões de P-A com a própria demografia, podem ser considerados ainda insipientes e de menor peso relativamente aos fundamentos e à expressão do primeiro mito.

Pode ser que o novo mito não tenha se mostrado suficientemente forte para contestar antigos pressupostos e/ou o campo ainda não teve o tempo e a maturidade necessários para fortificar-se em limites próprios. No entanto, na busca pela superação de limites disciplinares e de visões deterministas, devemos evitar o entrincheiramento da autodisciplinarização de P-A, mantendo-nos sempre abertos a outros olhares e formas de produzir conhecimento. 


\section{Referências}

ALMEIDA, M. Simetria e entropia: sobre a noção de estrutura de Lévi-Strauss. Revista de Antropologia, v. 42, n. 1-2, p. 163-197, 1999.

ALVES, J. E. D. População, desenvolvimento e sustentabilidade: perspectivas para a CIPD pós2014. Revista Brasileira de Estudos de População, v. 31, n. 1, p. 219-230, 2014.

ASHFORD, L. What was Cairo? The promise and reality of ICPD. Population Reference Bureau. 2014.

BARBIERI, A. Demographic mobility, the environment, and use of the land in border areas: a multi-scale approach. Revista Brasileira de Estudos de População, v. 24, n. 2, p. 225-246, 2007.

BECK, U. Risk society - Towards a new modernity. SAGE Publications, 1992.

BECKER, B. K. Amazônia. São Paulo: Ática, 1990.

BERQUÓ, E. As posições da OMS nas conferências de população da ONU nos últimos 50 anos. In: WONG, L. R. et al. Cairo+20: perspectivas de la agenda de población y desarrollo sostenible después de 2014. Rio de Janeiro: Alap, 2014. p. 17-22.

BILSBORROW, R. E. Population pressures and agricultural development in development countries: a conceptual framework and recent evidence. World Development, v. 15, n. 2, p. 183-203, 1987.

BILSBORROW, R.; GEORGES, M. Population change and agricultural intensification in developing countries. In: ARIZPE, L.; STONE, M.; MAJOR, D. (Ed.). Population \& environment: rethinking the debate. Bouler, CO: Westview Press, 1994.

BIRDSALL, N. Analytical approaches to the relationship of population growth and development. Population and Development Review, v. 3, n. 1-2, p. 63-102, 1977.

BODANSKY, D. The history of the global climate change regime. In: LUTERBACHER, U.; SPRINZ, D. F. (Ed.). International relations and global climate change. Cambridge, MA; London: The MIT Press, 2001. p. 23-40.

BOURDIEU, P. Le champ scientifique. Actes de la recherche en sciences sociales. Paris: Ed. Du Seuil, 1976.

Os usos sociais da ciência. São Paulo: Ed. Unesp, 2004.

BREMNER, J.; BILSBORROW, R. Population dynamics and millennium development goal 7. In: POPULATION-ENVIRONMENT RESEARCH NETWORK (PERN) CYBERSEMINAR. 5-15 September 2005.

CALDWELL, J. The global fertility transition: the need for unifying theory. Population and Development Review, v. 23, n. 4, p. 803-812, 1997.

CARMO, R. L.; D’ANTONA, Á. de O. Transição demográfica e a questão ambiental: para pensar população e ambiente. In: D’ANTONA, A. O.; CARMO, R. L. (Org.). Dinâmicas demográficas e ambiente. Campinas-SP: Nepo/Unicamp, 2011. p. 13-23.

CARMO, R. L.; JOHANSEN, I. C. Entrevista com George Martine. Ideias, v. 6, n. 1, p. 291-320, 2015.

CARVALHO, J. A. M.; GARCIA, R. A. O envelhecimento da população brasileira: um enfoque demográfico. Cadernos de Saúde Pública, Rio de Janeiro, v. 19, n. 3, p. 725-733, 2003.

CASTRO, M. C. Spatial demography: an opportunity to improve policy making at diverse decision levels. Population Research and Policy Review, v. 26, n. 5, p. 477-509, 2007.

COALE, A. J.; HOOVER, E. M. Population growth and economic development in low income countries. Princeton: Princeton University Press, 1958. 
CONTI, L. Ecologia; capital, trabalho e ambiente. São Paulo: Hucitec, 1986.

CNUMAD - Conferência das Nações Unidas sobre o Meio Ambiente e Desenvolvimento. Agenda 21. Brasília: Câmara dos Deputados, 1995 (Série Ação Parlamentar, n. 56).

CÔRTES, J. C.; D’ANTONA, Á. O. Dinâmicas no uso e cobertura da terra: perspectivas e desafios da Demografia. Revista Brasileira de Estudos de População, v. 31, n. 1, p. 191-210, 2014.

EHRLICH, P. R. The population bomb. Sierra Club / Balantine Books, 1968.

FAO - Food and Agriculture Organization of the United Nations. Forest resources assessment 1990 - Tropical countries. Roma: FAO, 1993 (Forestry Paper, n. 112).

Paper, n. 124).

Forest resources assessment 1990 - Global synthesis. Roma: FAO, 1995 (Forestry

Forest resources assessment 1990 - Survey of tropical forest cover and study of change processes. Roma: FAO, 1996 (Forestry Paper, n. 130).

Population in deforestation assessment. Development of demographic data at substate level and study of relation between population and deforestation in Brazil. Final Report. Roma: FAO, 1998.

FEARNSIDE, P. M. Developpement agricole et deforestation en Amazonie Bresilienne. Cahiers D’orstom, Sciences Humaines, v. 27, n. 1-2, p. 235-253, 1991.

. Deforestationin Brazilian Amazonia: the effect of population and land tenure. Ambio, v. 22, n. 8, p. 537-545, 1993 a.

Forests or fields: a response to the theory that tropical forest conservation poses a threat to the poor. Land Use Policy, v. 10, n. 2, p. 108-121, $1993 \mathrm{~b}$.

GUEDES, G.; OJIMA, R. Território, mobilidade populacional e ambiente. Governador Valadares, MG: Editora Univale, 2012.

HIRSCHMAN, C. Population and development: what do we really know? In: CONFERENCE ON DEVELOPMENT CHALLENGES FOR THE TWENTY-FIRST CENTURY, New York, 2004. Anais... New York: Cornell University Press, 2004.

HOGAN, D. J.; VIEIRA, P. F. Dilemas socioambientais e desenvolvimento sustentável. Campinas, SP: Unicamp, 1992.

HOGAN, D. J. A relação entre população e meio ambiente: desafios para a demografia. In: TORRES, H. G.; COSTA, H. (Ed.). População e meio ambiente: debates e desafios. São Paulo: Editora Senac, 2000.

Crescimento demográfico e meio ambiente. Revista Brasileira de Estudos de População, v. 8, n. 1-2, p. 61-71, 1991.

. Crescimento populacional e desenvolvimento sustentável. Lua Nova, n. 31, p. 57-78, 1993.

. Demographic dynamics and environmental change in Brazil. Ambiente e Sociedade, v. IV, n. 9, p. 1-30, 2001.

População e meio-ambiente. Campinas: Unicamp, 1989 (Textos Nepo, n. 16).

HOGAN, D. J.; BERQUÓ, E.; COSTA, H. (Org.). Population and environment in Brazil: Rio+10. 1. ed. Campinas, SP: MPC Artes Gráficas de Papel, 2002. v. 01.

HUMMEL, D. et al. Inter-and transdisciplinary approaches to population - environment research for sustainability aims: a review and appraisal. Population and Environment, v. 34, n. 4, p. 481-509, 2013. 
HUNTER, L. M. The environmental implications of population dynamics. Santa Monica, CA: RAND Corporation, 2000.

IANNI, O. O trabalhador rural em busca da terra. Encontros com a Civilização Brasileira, n. 11, p. 89-100, 1979a.

Ditadura e agricultura. O desenvolvimento do capitalismo na Amazônia: 1964-1978. Rio de Janeiro: Civilização Brasileira, 1979b (Retratos do Brasil, 131).

KEYFITZ, N. Population growth, development and the environment. Population Studies, n. 50, p. 335-359, 1996.

LEFF, E. La interdisciplinariedad en las relaciones población-ambiente. Hacia un paradigma de demografía ambiental. In: IZAZOLA, H.; LERNER, S. (Comp.). Población y ambiente: ¿nuevas interrogantes a viejos problemas? Mexico: Sociedad Mexicana de Demografía, 1993. p. 27-48.

LESTHAEGHE, R. The unfolding story of the second demographic transition. Population and Development Review, v. 36, n. 2, p. 211-251, 2010.

LEVI-STRAUSS, C. A estrutura dos mitos. In: LEVI-STRAUSS, C. (Ed.). Antropologia estrutural. Rio de Janeiro: Tempo Brasileiro, 1975.

Mito e significado. Lisboa: Edições 70, 1963.

LUTZ, W. Population and environment - What do we need more urgently: better data, better models, or better questions? In: ZABA, B.; CLARKE, J. (Eds.). Environment and population change. Liège, Belgium: Derouaux Ordina, 1994.

LUTZ, W.; PRSKAWETZ, A.; SANDERSON, W. Introduction. In: LUTZ, W.; PRSKAWETZ, A.; SANDERSON, W. (Ed.). Population and environment: methods of analysis. New York: Population Council, 2002.

MALTHUS, T. An essay on the principle of population. As it affects the future improvement of society with remarks on the speculations of Mr. Godwin, M. Condorcet and other writers. 1. ed. London: J. Johnson in St Paul's Church-yard, 1798. Disponivel em: 〈https://archive.org/details/ essayonprincipl00malt>. Acesso em: 12 ago. 2015.

MARANDOLA JR., E.; HOGAN, D. J. Em direção a uma demografia ambiental? Avaliação e tendências dos estudos de população e ambiente no Brasil. Revista Brasileira de Estudos de População, v. 24, n. 2, p. 191-223, 2007.

MARTINE, G. Ciclos e destinos da migração para áreas de fronteira na era moderna: uma visão geral. Brasília-DF: ISPN, 1992 (Documento de trabalho, n. 12).

Desenvolvimento, dinâmica demográfica e meio ambiente: repensando a agenda ambiental brasileira. Brasília-DF: ISPN, 1991 (Documento de trabalho, n. 1).

. Implicações da redistribuição populacional para a rediscussão da agenda ambiental brasileira. Brasília-DF: ISPN, 1993 (Documento de trabalho, n. 19).

The sustainable use of space: advancing the population/environment agenda. In: POPULATION-ENVIRONMENT RESEARCH NETWORK (PERN) CYBERSEMINAR. 2001. Disponivel em: 〈https://populationenvironmentresearch.org/pern_files/papers/Martine_paper.pdf〉. Acesso em: 10 ago. 2015.

. (Ed.). População e sustentabilidade na era das mudanças ambientais globais: contribuições para uma agenda brasileira. Belo Horizonte: Abep, 2012.

MARTINS, J. S. Impasses políticos dos movimentos sociais na Amazônia. Tempo Social, v. 1, n. 1, p. 131-148, 1989. 
MCCRACKEN, S. D.; SIQUEIRA, A.; MORAN, E. F.; BRONDIZIO, E. Land use patterns on an agricultural frontier: insights and examples from a demographic perspective. In: WOOD, C.; PORRO, R. (Ed.). Deforestation and land use in the Amazon. Gainesville, Florida: University Press of Florida, 2002. p. 162-192.

MELLO, L.; HOGAN, D. J. População, consumo e meio ambiente. In: XV ENCONTRO NACIONAL DE ESTUDOS POPULACIONAIS. Anais... Caxambu, MG: Abep, 2006.

NATIONAL RESEARCH COUNCIL. Population, land use, and environment. Research directions. Washington, D.C.: National Academies Press, 2005.

NESS, G. Population and the environment: frameworks for analysis. EPAT/MUCIA, 1994 (Working Paper, n. 10).

OJIMA, R.; HOGAN, D. J. Mobility, urban sprawl and environmental risks in Brazilian urban agglomerations: challenges for the urban sustainability in a developing country. In: DE SHERBINIIN, A. et al. (Org.). Urban population-development-environment dynamics in the developing world: case studies and lessons learned. 1. ed. Paris: Committee for International Cooperation in National Research in Demography (CICRED), 2009. v. 1, p. 281-316.

OJIMA, R. Demografia e ciência: reflexões epistemológicas sobre a ciência das populações. Natal: Demografia do Nordeste. 2015. Mimeografado. Disponível em: http://demografianordeste. blogspot.com.brr. Acesso em: 31 mar. 2016.

OLIVEIRA, F. Malthus e Marx, falso encanto e dificuldade radical. Campinas, SP: Nepo/Unicamp, 1985.

O’NEILL, B.; DALTON, M.; FUCHS, R.; JIANG, L.; PACHAURI, S.; ZIGOVA, K. Global demographic trends and future carbon emissions. PNAS, v. 107, n. 41, p. 17521-17526, 2010.

PAN, W. K. Multilevel and spatial models to examine the relationship between population and environment: a case study of the Ecuadorian Amazon. Chapel Hill, NC: Department of Biostatistics, University of North Carolina at Chapel Hill, 2003.

PERN. Population-Environment Research Network. Disponível em: 〈https://www. populationenvironmentresearch.org〉. Acesso em: 10 ago. 2015.

PHILIPPI JR., A.; TUCCI, C. E.; HOGAN, D.; NAVEGANTES, R. Interdisciplinaridade em ciências ambientais. São Paulo: Signus Editora, 2000.

RANDERS, J.; MEADOWS, D. The carrying capacity of our global environment: a look at the ethical alternatives. In: DALY, H. E. (Ed.). Towards a steady-state economy. San Francisco: W. H. Freeman and Company, 1975. p. 283-306.

RIOS-NETO, E. A relação entre população e desenvolvimento 15 anos após a Conferência do Cairo. In: ABEP; UNFPA. Brasil, 15 anos após a Conferência do Cairo. Campinas: Abep, 2009. p. 13-56.

SAWYER, D. Ocupación y desocupación de la frontera agricola en el Brasil: un ensayo de interpretación estructural y espacial. In CEPAL/PNUMA (Ed.). Expansion de la frontera agropecuaria y medio ambiente en America Latina. Madri: Nacionaes Unidas, 1983. p. 79-104.

População, meio ambiente e desenvolvimento no Brasil. Brasília: ISPN, 1993.

. Urbanização da fronteira agrícola no Brasil. In: LAVINAS, L. (Ed.). A urbanização da fronteira. Rio de Janeiro-RJ: UFRJ, 1987. v. 1, p. 43-57.

SAWYER, D.; PINHEIRO, S. Dinâmica demográfica das regiões de fronteira. In: IV ENCONTRO NACIONAL DE ESTUDOS POPULACIONAIS. Anais... São Paulo: Abep, 1984. p. 2017-2047.

SPRINGER. Population and Environment. Disponível em: 〈http://link.springer.com/journal/11111〉. Acesso em: 5 ago. 2015. 
STONICH, S. The dynamics of social processes and environmental destruction: a Central American case study. Population and Development Review, v. 15, n. 2, p. 269-296, 1989.

THOMPSON, V. Editorial. Journal of Population, v. 1, n. 1, p. 3-4, 1978.

TORRES, H. G.; COSTA, H. (Org.). População e meio ambiente: debates e desafios. São Paulo: Senac, 2000.

UNITED NATIONS. Programme of action of the International Conference on Population Development. 20th Anniversary Edition. United Nations, $2014 \mathrm{a}$.

. Framework of actions for the follow-up to the Programme of Action of the International Conference on Population and Development. United Nations, 2014b.

Relatório da Conferência Internacional sobre População e Desenvolvimento. Cairo, Egito 5 a 13 de setembro de 1994.

. United Nations Report of the United Nations Conference on Sustainable Development. New York: United Nations, 2012.

VIOLA, E.; LEIS, H. A evolução das políticas ambientais no Brasil, 1971-1991. In: HOGAN, D. J.; VIEIRA, P. F. (Ed.). Dilemas socioambientais e desenvolvimento sustentável. Campinas, SP: Unicamp, 1992.

VOSS, P. R. Demography as a spatial social science. Population Research Policy Review, v. 26, n. 5, p. 457-476, 2007.

WALKER, R.; HOMMA, A. K. O. Land use and land cover dynamics in the Brazilian Amazon: an overview. Ecological Economics, v. 18, n. 1, p. 67-80, 1996.

WALSH, S. J. et al. Scale-dependent relationships between population and environment in northeastern Thailand. Photogrammetric Engineering and Remote Sensing, v. 65, n. 1, p. 97, 1999.

\section{Sobre o autor}

Álvaro de Oliveira D’Antona é doutor em Ciências Sociais. Livre-docente da Faculdade de Ciências Aplicadas da Universidade Estadual de Campinas (Unicamp). Professor do Mestrado Interdisciplinar em Ciências Humanas e Sociais Aplicadas e do Programa de Pós-graduação em Demografia (Unicamp). Colaborador do Núcleo de Estudos de População "Elza Berquó" (Nepo-Unicamp).

\section{Endereço para correspondência}

Faculdade de Ciências Aplicadas (FCA/Unicamp)

Rua Pedro Zaccaria, 1300, Caixa Postal 1068

13484-350 - Limeira-SP, Brasil

\section{Abstract}

From the Malthusian myth to that of reciprocal relations - the interdisciplinary constitution of the Population and Environment field

A review on the Population and Environment (P-E) field, mainly carried out in the 1990s, is accomplished through: 1 . Prospecting articles indexed in international databases; 2 . Identifying the structuring instances of the field, essential for its identity and for validating the produced 
knowledge; 3. Indicating the relationship of the field with the themes of Population, Development and Environment included in the UN conferences. As a result, we notice that the scientific production published in the major journals and events of population studies progressively distanced themselves from the Malthusian myth, aiming toward the search for reciprocal relations between population and environment, a second myth. The existence of characteristic issues, axes, and identities, treated by a well-defined set of scientists can also be found. Among the two essential myths, P-E has expanded as an interdisciplinary field under the effects of dialogues with the social and environmental sciences. Noncompliant to disciplinary limits, it faces the theoretical-epistemological and empirical difficulties of a field still under construction, while experiencing tensions with demography, an important discipline of its program matrix.

Keywords: Population and Environment. Demography. Research. Researchers. Field.

\section{Resumen}

Del mito maltusiano al de las relaciones recíprocas - la constitución interdisciplinaria del campo de Población y Medio Ambiente

Se hace una revisión de la constitución del campo de Población y Medio Ambiente (P-MA), especialmente en los años 1990, a través de: 1. prospección de artículos en bases de datos internacionales indexadas; 2 . identificación de los cuerpos estructurales de ese campo, esenciales para su identidad y para validar el conocimiento producido; 3. identificación de la relación del campo con los temas de Población, Desarrollo y Medio Ambiente vistos en las conferencias de la ONU. Como resultado, vemos que la producción científica publicada en las principales revistas y eventos de estudios de población se apartó gradualmente del mito maltusiano para volcarse hacia la búsqueda de relaciones recíprocas entre población y medio ambiente, un segundo mito. También se constata la existencia de temas característicos ejes e idiosincrásicos tratados por un conjunto de científicos bien definido. Entre los dos principales mitos, P-MA se ha expandido como un campo interdisciplinario bajo el efecto de los diálogos con las ciencias sociales y ambientales. Enfrenta las dificultades teórico-epistemológicas y empíricas de un campo en formación sin atenerse a límites disciplinarios mientras que experimenta tensiones con la demografía, disciplina importante de su matriz programática

Palabras clave: Población y Medio Ambiente. Demografía. Investigación. Investigadores. Campo de la población. 